\title{
Does family communication moderate the association between adverse childhood experiences and emotional and behavioural problems?
}

Miriama Lackova Rebicova ${ }^{1,2^{*}}$, Zuzana Dankulincova Veselska ${ }^{1,2}$, Daniela Husarova ${ }^{1,2}$, Daniel Klein ${ }^{3}$, Andrea Madarasova Geckova ${ }^{1,2,4}$, Jitse P. van Dijk ${ }^{2,4,5}$ and Sijmen A. Reijneveld ${ }^{5}$

\begin{abstract}
Background: Adverse childhood experiences (ACEs) and poor family support and communication can increase emotional and behavioural problems (EBP). Therefore, we assessed the association of difficult communication with mother and with father separately with both emotional and behavioural problems (EBP), and whether adolescents' communication with mother and with father moderates the association of adverse childhood experiences (ACE) with the EBP of adolescents.

Methods: We used data from the Health Behaviour in School-aged Children study conducted in 2018 in Slovakia, comprising 5202 adolescents aged from 11 to 15 (mean age 13.53; 49.3\% boys). EBP were measured using the Strengths and Difficulties Questionnaire. We used generalized linear regression adjusted for age, gender and family affluence to explore the modification of the associations between ACE and EBP by communication (easy vs. difficult communication) with mother and father.

Results: Difficult communication or a complete lack of communication due to the absence of mother and father increased the probability of emotional (exp (b): 0.96, 95\% Cl: 0.92|1.00; and 0.95, 95\% Cl: $0.91 \mid 0.99$, respectively) and also of behavioural problems (exp (b): 0.96, 95\% Cl: 0.92|1.00; and 0.94, 95\% Cl: 0.90|0.97, respectively). We found a statistically significant interaction of communication with father on the association of ACE with EBP, showing that the joint effects were less than multiplicative.
\end{abstract}

Conclusion: Difficult communication with mother and father is related to EBP among adolescents, and adolescents' communication with father moderates the association of ACE with both emotional and behavioural problems among adolescents.

Keywords: Family communication, Adverse childhood experiences, Emotional problems, Behavioural problems, Adolescents

\footnotetext{
*Correspondence: miriama.rebicova@upjs.sk

'Department of Health Psychology and Research Metodology, Medical Faculty, PJ Safarik University, Trieda SNP 1, 04001 Kosice, Slovak Republic

${ }^{2}$ Graduate School Kosice Institute for Society and Health, PJ Safarik University, Trieda SNP 1, 04001 Kosice, Slovak Republic

Full list of author information is available at the end of the article
}

(c) The Author(s). 2020 Open Access This article is licensed under a Creative Commons Attribution 4.0 International License, which permits use, sharing, adaptation, distribution and reproduction in any medium or format, as long as you give appropriate credit to the original author(s) and the source, provide a link to the Creative Commons licence, and indicate if changes were made. The images or other third party material in this article are included in the article's Creative Commons licence, unless indicated otherwise in a credit line to the material. If material is not included in the article's Creative Commons licence and your intended use is not permitted by statutory regulation or exceeds the permitted use, you will need to obtain permission directly from the copyright holder. To view a copy of this licence, visit http://creativecommons.org/licenses/by/4.0/ The Creative Commons Public Domain Dedication waiver (http://creativecommons.org/publicdomain/zero/1.0/) applies to the data made available in this article, unless otherwise stated in a credit line to the data. 


\section{Background}

Adverse childhood experiences (ACE) regard a wide range of negative events that occur at a young age, such as abuse and/or neglect towards a child, domestic violence towards a youth's mother, household substance abuse, household mental illness, parental separation/divorce and other events $[1,2]$. Experiences of long-term ACE can cause serious emotional and behavioural problems (EBP) throughout the life of a child [1,3-5]. In addition, ACE has been shown to have a dose-response relationship with various mental health conditions, including depression, anxiety, panic reactions, hallucinations, psychoses and suicide attempts [6-14]. The mechanisms for these associations may involve the modified physiological development of children due to experienced chronic stress $[15,16]$ or the adoption of behaviours that harm their physical and mental health $[3,17]$.

Family factors, e.g. family support and family communication, are associated with positive adolescent development, i.e. are protective factors $[18,19]$. Worsening or even a complete lack of family support and communication was found to be associated with a decline in adolescent mental health, which points to the importance of family communication with both parents [20-22] and to the nature of family relationships in adolescent health [22, 23]. Worse child-parent family relationships were associated with anxiety and depression [21, 23-26]. Even more, in relationships between adolescents and parents with insufficient or lacking communication, adolescents were found to be at increased risk of mental health problems [21, 25-28]. Most of the available evidence has focused on the role of overall communication with parents on adolescents' mental health regardless of the gender of the parent [18, 19, 21, 22]. Moreover, no attention has been paid to the potential role of communication with mother and with father as moderators of the relationship between ACE and EBP.

Low socioeconomic position may be considered as one of the ACE itself and causes early life stress [1, 27, 28]. More experience with financial stress was found to be associated with poorer mental health [29], and also to be related to more behavioural problems $[1,30]$.

The aim of this study is to assess the association of difficult communication with mother and with father separately with both emotional and behavioural problems, and whether adolescents' communication with mother and with father moderates the association of ACE with both emotional and behavioural problems among adolescents.

\section{Methods}

\section{Sample and procedure}

We used data from the Health Behaviour in School-aged Children (HBSC) study conducted in 2018 in Slovakia. More detailed information about two-step sampling process and procedure used to acquire this nationally representative sample could be found in our previously published paper [1, 31]. In the first step, 140 larger and smaller elementary schools located in rural as well as urban areas from all regions of Slovakia were asked to participate. These were randomly selected from a list of all eligible schools in Slovakia obtained from the Slovak Institute of Information and Prognosis for Education. The school response rate (RR) was $77.9 \%$. In the second step, we obtained data from 8405 adolescents from the fifth to ninth grades of the elementary schools in Slovakia in the target group of 11 to 15 years old (mean age $13.43 ; 50.9 \%$ boys); one class per grade was selected. Respondents with missing responses were excluded (3203), leading to a final sample of 5202 adolescents (mean age $13.53 ; 49.3 \%$ boys).

The study was approved by the Ethics Committee of the Medical Faculty at the P.J. Safarik University in Kosice (16 N/2017). Parents were informed about the study via the school administration and could opt out if they disagreed with their child's participation. Then, written consent from study participants was obtained. Participation in the study was fully voluntary and anonymous, with no explicit incentives provided for participation.

\section{Measures}

Emotional and behavioural problems (EBP) were measured using the Strengths and Difficulties Questionnaire (SDQ), which includes 25 items on psychological attributes [32], of which we used the 20 problem items. Response categories were: not true (0), somewhat true (1), certainly true (2). Detailed information about compute of emotional (internalizing) and behavioural (externalizing) problems could be found in our previously published paper $[1,33]$. Cronbach's alpha in our sample was 0.73 for the whole scale, and 0.71 for the internalizing and externalizing subscales, respectively.

Adverse childhood experiences ( $A C E$ ) were measured using a series of questions on events: "Have you ever experienced any of the following serious events? (Death of a brother/sister, Death of your father/mother, Death of somebody else you love, Long or serious illness of yourself, Long or serious illness of one of your parents or of someone else close to you, Problems of one of your parents with alcohol or drugs, Repeated serious conflicts or physical fights between your parents, Separation/divorce of your parents, Separation of your parents due to work abroad, Moving to another house/flat, or city/village, Transfer to another school). Questions about childhood abuse and neglect were not included in the ACE questionnaire measured for this study. The response categories were "yes" and "no". More detailed information about creating a sum score of ACE experienced could be found in our previously published paper [1]. Based on the literature and the distribution of categories, 
we next categorised the number of ACE into three categories: no ACE, one or two ACE and three or more ACE $[1,34-36]$.

Communication with parents/stepparents was measured with the question "How easy is it for you to talk to the following persons about things that really bother you? (mother, father, stepmother, stepfather)". The response categories were very easy / easy / difficult / very difficult / don't see or have this person. Questions about communication with mother and stepmother were merged, as were questions about communication with father and stepfather. Both combined variables were dichotomized into two categories - easy / difficult or don't see or have this person. We combined these two categories (difficult communication / don't have this person), because in both situations the parent does not fulfil his/her role.

Socioeconomic position was measured using the Family Affluence Scale III (FAS-III), which consists of six questions: "Does your family own a car, van or truck?" (No / Yes, one / Yes, two or more), "Do you have your own bedroom for yourself?" (Yes / No), "How many computers does your family own?" (None / One / Two / More than two), "How many bathrooms (room with a bath/shower or both) are in your home?" (None / One / Two / More than two), "Does your family have a dishwasher at home?" (Yes / No), "How many times did you and your family travel out of your country for a holiday/ vacation last year?" (Not at all / Once / Twice / More than twice). We computed sum score, which we converted into a ridit score ranging from 0 to 1 . We then created tertile categories of low (0 to 0.333 ), medium (0.334 to 0.666$)$ and high (0.667 to 1$)$ socioeconomic position [31, 37].

\section{Statistical analyses}

First, we described the sample using descriptive statistics in Table 1. Second, we assessed the association of communication with mother and with father with emotional problems and behavioural problems (Model 1). Third, we assessed the associations of the number of ACE and of communication with mother and with father with emotional problems and behavioural problems (Model 2). Finally, we explored the modification of the associations of ACE with emotional problems and behavioural problems by communication with mother and with father separately (Model 3). For these three steps we used generalized linear models adjusted for age, gender and family affluence. To overcome the problem of normality assumption of the dependent variable, the gamma distribution with log link function was used. Because of the $\log$ transformation of the dependent variable, the regression coefficients were transformed exponentially and displayed as such in Table 2 to show the effect of the independent variables on the non-transformed dependent variable. Statistical analyses were performed using SPSS v.20.

\section{Results}

\section{Background characteristics}

The background characteristics of the sample are presented in Table 1. We found that $15.2 \%$ of the study sample reported no ACE, $46.2 \%$ reported 1-2 ACE and $38.6 \% 3$ or more ACE (Table 1). Of the respondents, $79.3 \%$ reported easy communication with mother/step-mother and $67.7 \%$ easy communication with father/step-father.

\section{Associations of communication with mother and father with emotional problems and behavioural problems}

We assessed the association of communication with mother and with father with emotional problems and behavioural problems (Model 1). We found significant associations between adolescents' communication with parents (mother and father) and both emotional and behavioural problems. Difficult communication or a complete lack of communication due to the absence of mother and of father increased the probability of emotional and also of behavioural problems.

\section{Associations of the number of ACE and of communication with mother and father with emotional problems and behavioural problems}

We assessed the associations of the number of ACE and of communication with mother and with father with emotional problems and behavioural problems (Model 2). We found both ACE and adolescents' communication with parents (mother and father) to be significantly associated with both emotional and behavioural problems. More $\mathrm{ACE}$ and difficult communication or a complete lack of communication due to the absence of mother and of father increased the probability of emotional and also of behavioural problems (Model 2).

\section{Moderation of the associations between ACE and EBP by communication with parents (mother and father)}

In Model 3, we assessed the interaction of $\mathrm{ACE}$ and communication with mother and with father regarding both emotional and behavioural problems. We found a statistically significant interaction of communication with father for the associations of ACE with emotional and behavioural problems. The odds ratio could be interpreted as meaning that having experienced ACE and difficult communication, or a complete lack of communication due to the absence of father, decreased the probability of emotional and even more of behavioural problems when compared to the multiplicative model. We did not find a statistically significant interaction of ACE with communication with mother on either emotional 
Table 1 Descriptive statistics of the sample (HBSC-study, Slovakia 2018, $11-15$ years old, $N=5202$ )

\begin{tabular}{|c|c|}
\hline & Total \\
\hline & $\boldsymbol{N}=5202$ \\
\hline \multicolumn{2}{|l|}{ Gender $(N, \%)$} \\
\hline Boys & $2562(49.3)$ \\
\hline Age (mean, SD) & 13.531 .31 \\
\hline \multicolumn{2}{|l|}{ FAS $(N, \%)$} \\
\hline Low & $1466(28.2)$ \\
\hline Middle & 1508 (29.0) \\
\hline High & 2029 (39.0) \\
\hline \multicolumn{2}{|l|}{$\operatorname{ACE}(N, \%)$} \\
\hline No ACE & $790(15.2)$ \\
\hline $1-2 \mathrm{ACE}$ & $2402(46.2)$ \\
\hline 3 and more ACE & 2010 (38.6) \\
\hline \multicolumn{2}{|c|}{$\begin{array}{l}\text { Communication with } \\
\text { mother/stepmother }(N, \%)\end{array}$} \\
\hline Easy & $4092(79.3)$ \\
\hline \multicolumn{2}{|l|}{$\begin{array}{l}\text { Communication with } \\
\text { father/stepfather }(N, \%)\end{array}$} \\
\hline Easy & $3514(67.7)$ \\
\hline \multicolumn{2}{|c|}{$\begin{array}{l}\text { Emotional and behavioural } \\
\text { problems (mean, SD) }\end{array}$} \\
\hline Emotional problems & 15.133 .34 \\
\hline Behavioural problems & 16.483 .28 \\
\hline
\end{tabular}

HBSC-study Health Behaviour in School-Aged Children study, $N$ number of respondents, FAS Family affluence, $A C E$ adverse childhood experiences, $S D$ standard deviation

Note. Only valid percentages are presented; missing values: FAS $=119(3.8 \%)$, communication with mother $=42(0.8 \%)$, communication with father $=11(0.2 \%)$

or behavioural problems, showing that for the mother the associations of ACE with EBP were fully multiplicative (Model 3).

\section{Discussion}

The present study shows that EBP among adolescents are more likely in case of difficult communication with parents. We also found an interaction, i.e. that communication with the father moderated the association of ACE with EBP.

We found that difficult communication with both parents is related to emotional and to behavioural problems in adolescents, thus adding to the already existing evidence on overall importance of communication with parents [18-22]. Likewise, recent studies show that negative family interactions between parent and child are associated with higher levels of anxiety and depression [23, 38-40], whereas communication between the parents and the child may be influenced by several factors, such as a divorce of the parents $[41,42]$. Moreover, recent studies exploring father-child relationships have proposed an "activation relationship", where fathers also tend to encourage children to take risks, while at the same time ensuring their safety and security [43-47]. Family communication plays an important role in the occurrence of EBP in adolescence [41]. Difficult communication with mother and father during childhood and adolescence can have a deleterious effect on mental and physical health and on a healthy development, and our study shows that this also holds true for EBP.

Moreover, we found that adolescents' communication with father moderates the association of ACE with both emotional and behavioural problems among adolescents, but not the communication with mother. This shows that for communication with the mother, the effect of the combination of difficult communication and ACE is multiplicative, i.e. that the strength of the association of ACE with problems is multiplied by the presence of communication problems. However, for communication with the father this is true to a lesser degree. The OR for the interaction of communication with the father with ACE was lower than 1. This indicates that the joint effect of having both ACE and a difficult communication with father was less than multiplicative, i.e. hardly greater than the joint separate effects of having only ACE and of having a difficult communication with father. Such a difference in the role of communication with mother and with father may reflect perceived differences for the adolescent in the nature of the communication. Adolescents report that they talk more and prefer communication with their mothers than their fathers $[48,49]$, which may result from the fact that the relationship between mother and child is characterized more than father-child interactions by warmth, responsiveness and intimate exchanges [50]. However, previous studies have reported mostly on the different character of communication, whereas our study reveals that those differences result in higher risks for EBP in the case that difficulties or lack of communication, especially with mother, is combined with ACE. We presume that other factors may be involved here, which are linked to more ACE and/or difficult communication with parents and which are associated with a higher risk of more ACE. Adolescents with ACE and difficult communication with their parents might be more likely to get into the care system. In the care system, adolescents with ACE can be provided more specialised care (from e.g. psychologist, social worker), which may have a mitigating effect on the relationship between ACE, communication with parents and EBP.

\section{Strengths and limitations}

The main strengths of our study are its large nationally representative sample and its use of the well- 
Table 2 The association between communication with mother and with father and EBP, and the moderation of the associations between ACE and EBP by communication with mother and with father from generalized linear models adjusted for age, gender and FAS (exp (b) 95\% Confidence intervals) (Slovakia 2018, 11-15 years old, $N=5202$ )

\begin{tabular}{|c|c|c|c|c|c|c|}
\hline & \multicolumn{3}{|c|}{ Emotional problems } & \multicolumn{3}{|c|}{ Behavioural problems } \\
\hline & Model 1 & Model 2 & Model 3 & Model 1 & Model 2 & Model 3 \\
\hline \multicolumn{7}{|l|}{ Mother } \\
\hline \multicolumn{7}{|l|}{ ACE } \\
\hline 0 & & Ref. & Ref. & & Ref. & Ref. \\
\hline $1-2$ & & $1.03(1.01 \mid 1.04)^{* *}$ & $1.03(1.01 \mid 1.05)^{* *}$ & & $1.02(1.00 \mid 1.04)^{*}$ & $1.02(1.00 \mid 1.04)^{*}$ \\
\hline 3 and more & & $1.08(1.06 \mid 1.11)^{* * *}$ & $1.09(1.07 \mid 1.12)^{* * *}$ & & $1.08(1.06 \mid 1.09)^{* * *}$ & $1.08(1.07 \mid 1.11)^{* * *}$ \\
\hline \multicolumn{7}{|l|}{$\begin{array}{l}\text { Communication with } \\
\text { mother }\end{array}$} \\
\hline easy & Ref. & Ref. & Ref. & Ref. & Ref. & Ref. \\
\hline difficult & $0.11(0.10 \mid 0.13)^{* * *}$ & $1.12(1.11 \mid 1.13)^{* * *}$ & $1.14(1.09 \mid 1.19)^{* * *}$ & $0.10(0.09 \mid 0.12)^{* * *}$ & $1.11(1.09 \mid 1.12)^{* * *}$ & $1.13(1.08 \mid 1.16)^{* * *}$ \\
\hline $\begin{array}{l}\mathrm{ACE}^{*} \text { Communication } \\
\text { with mother }\end{array}$ & & & ns & & & ns \\
\hline 1-2 ACE*difficult & & & $0.98(0.93 \mid 1.02)$ & & & $0.98(0.94 \mid 1.03)$ \\
\hline $3 \geq$ ACE $^{*}$ difficult & & & $0.98(0.93 \mid 1.02)$ & & & $0.97(0.93 \mid 1.01)$ \\
\hline \multicolumn{7}{|l|}{ Father } \\
\hline \multicolumn{7}{|l|}{ ACE } \\
\hline 0 & & Ref. & Ref. & & Ref. & Ref. \\
\hline $1-2$ & & $1.02(1.00 \mid 1.04)^{*}$ & $1.03(1.01 \mid 1.05)^{* *}$ & & $1.02(1.00 \mid 1.03)$ & $1.03(1.01 \mid 1.04)^{*}$ \\
\hline 3 and more & & $1.07(1.06 \mid 1.09)^{* * *}$ & $1.09(1.07 \mid 1.12)^{* * *}$ & & $1.07(1.05 \mid 1.09)^{* * *}$ & $1.09(1.07 \mid 1.12)^{* * *}$ \\
\hline \multicolumn{7}{|l|}{$\begin{array}{l}\text { Communication with } \\
\text { father }\end{array}$} \\
\hline easy & Ref. & Ref. & Ref. & Ref. & Ref. & Ref. \\
\hline difficult & $0.11(0.09 \mid 0.12)^{* * *}$ & $1.11(1.09 \mid 1.12)^{* * *}$ & $1.15(1.11 \mid 1.18)^{* * *}$ & $0.09(0.08 \mid 0.11)^{* * *}$ & $1.09(1.07 \mid 1.11)^{* * *}$ & $1.14(1.10 \mid 1.17)^{* * *}$ \\
\hline $\begin{array}{l}\text { ACE*Communication } \\
\text { with father }\end{array}$ & & & * & & & $* *$ \\
\hline 1-2 ACE* difficult & & & $0.96(0.92 \mid 1.00)^{*}$ & & & $0.96(0.92 \mid 1.00)^{*}$ \\
\hline $3 \geq$ ACE $^{*}$ difficult & & & $0.95(0.91 \mid 0.99)^{*}$ & & & $0.94(0.90 \mid 0.97)^{* *}$ \\
\hline
\end{tabular}

ns not significant, ${ }^{*} p<.05{ }^{* *} p<.01{ }^{* * *} p<.001$

The effect of coefficients is multiplicative

established HBSC methodology. However, this study has also some limitations. First, we used self-reported questionnaires, which can be sensitive for adolescents. However, confidentiality as well as privacy were provided by the self-administration of the questionnaires in the absence of teachers, which prevented potential bias due to data collection. Moreover, previous research has shown the validity of self-reported measurement of EBP as well as ACE [51, 52]. A second limitation is that HBSC study is cross-sectional, which make it impossible to formulate conclusive statements about causality. A third limitation of our study is that we could not discriminate the two categories 'difficult communication' and 'don't see or have this person'; because the number of respondents in the category 'don't see or have this person' was too small. For future research, it would be appropriate to monitor the impact of these two categories separately.

\section{Implications}

Difficult communication with mother and father was related to EBP among adolescents. We also found that communication with father moderates the association of ACE with both emotional and behavioural problems among adolescents, but not the communication with mother. For communication with mother, the effect of the combination of difficult communication and ACE is multiplicative. However, for father this holds only to a lesser degree. Therefore, special attention should be paid to the adolescents facing the situation of difficult communication with mother and more ACE. This implies that improvement in communication between a parent and child could help decrease the probability of EBP in adolescents with ACE.

Regarding future research, we in particular need longitudinal studies to assess pathways and existing mechanisms on the associations of ACE, communication with 
parents and EBPs. Finally, further research is needed to examine other factors that enter into the relationship between ACE, communication with parents and EBP, e.g. care providers (psychologist, social worker). Investigating other factors (e.g. care provided) that enter into relationship between ACE, communication with parents and EBP can bring a clearer view of adolescents with EBP and may help to decrease the probability of EBP among adolescents.

\section{Conclusion}

Difficult communication with mother and father is related to EBP among adolescents, and adolescents' communication with father moderates the association of ACE with both emotional and behavioural problems among adolescents.

\section{Abbreviations}

ACE: Adverse childhood experiences; EBP: Emotional and behavioural problems; FAS: Family affluence

\section{Acknowledgements}

Not applicable.

\section{Authors' contributions}

MLR conceived of the study, participated in its design and coordination and drafted the manuscript, participated in the interpretation of the data ZDV conceived of the study, participated in its design and coordination, participated in the interpretation of the data, helped to draft the manuscript, provided supervision. DH participated in the interpretation of the data, helped to draft the manuscript, provided supervision. DK participated in the interpretation of the data. AMG conceived of the study, participated in the interpretation of the data, provided supervision. JPVD provided supervision. SAR participated in the interpretation of the data, provided supervision. All authors read and approved the final manuscript.

\section{Funding}

This work was supported by the Research and Development Support Agency under Contract No. APW-15-0012, APW-18-0070 and APW-17-0568. All funding bodies provided financial resources for data collection but otherwise did not influence study design, data collection, analysis or interpretation of data.

\section{Availability of data and materials}

The datasets used and/or analysed during the current study are available from the corresponding author on reasonable request.

\section{Ethics approval and consent to participate}

All procedures performed in the study were in accordance with the 1964 Helsinki declaration and its later amendments or comparable ethical standards. The study was approved by the Ethics Committee of the Medical Faculty at the P.J. Safarik University in Kosice (16 N/2017). Parents were informed about the study via the school administration and could opt out if they disagreed with their child's participation. Then, written consent from study participants was obtained.

\section{Consent for publication}

Not applicable.

\section{Competing interests}

The authors declare that they have no competing interests.

\section{Author details}

${ }^{1}$ Department of Health Psychology and Research Metodology, Medical Faculty, PJ Safarik University, Trieda SNP 1, 04001 Kosice, Slovak Republic. ${ }^{2}$ Graduate School Kosice Institute for Society and Health, PJ Safarik University,
Trieda SNP 1, 04001 Kosice, Slovak Republic. ${ }^{3}$ Institute of Mathematics, Faculty of Natural Sciences, P.J. Safarik University, Srobarova 2, 04154 Kosice, Slovak Republic. ${ }^{4}$ Olomouc University Social Health Institute, Palacky University, Univerzitni 22, 77111 Olomouc, Czech Republic. ${ }^{5}$ Department of Community and Occupational Medicine, University Medical Center Groningen, University of Groningen, Antonius Deusinglaan 1, 9713, AV, Groningen, the Netherlands.

Received: 8 November 2019 Accepted: 4 August 2020

Published online: 20 August 2020

\section{References}

1. Lackova Rebicova M, Dankulincova Veselska Z, Husarova D, Madarasova Geckova A, van Dijk JP, Reijneveld SA. The number of adverse childhood experiences is associated with emotional and behavioral problems among adolescents. Int J Environ Res Public Health. 2019;16(13):2446. https://doi. org/10.3390/ijerph16132446.

2. DeLisi M, Alcala J, Kusow A, Hochstetler A, Heirigs M, Caudill J, Trulson C, Baglivio M. Adverse childhood experiences, commitment offense, and race/ ethnicity: are the effects crime-, race-, and ethnicity-specific? Int J Environ Res Public Health. 2017;14(3):331. https://doi.org/10.3390/ijerph14030331.

3. Danese A, McEwen BS. Adverse childhood experiences, allostasis, allostatic load, and age-related disease. Physiol Behavior. 2012;106(1):29-39. https:// doi.org/10.1016/j.physbeh.2011.08.019.

4. Sala M, Caverzasi E, Lazzaretti M, Morandotti N, De Vidovich G, Marraffini E, Gambini F, Isola M, De Bona M, Rambaldelli G, d'Allio G. Dorsolateral prefrontal cortex and hippocampus sustain impulsivity and aggressiveness in borderline personality disorder. J Affect Disord. 2011;131(1-3):417-21. https://doi.org/10.1016/j.jad.2010.11.036.

5. Cohen RA, Grieve S, Hoth KF, Paul RH, Sweet L, Tate D, Gunstad J, Stroud L, McCaffery J, Hitsman B, Niaura R. Early life stress and morphometry of the adult anterior cingulate cortex and caudate nuclei. Biol Psychiatr. 2006; 59(10):975-82. https://doi.org/10.1016/j.biopsych.2005.12.016.

6. Oh DL, Jerman P, Boparai SK, Koita K, Briner S, Bucci M, Harris NB. Review of tools for measuring exposure to adversity in children and adolescents. J Pediatr Health Care. 2018;32(6):564-83. https://doi.org/10.1016/j.pedhc.2018. 04.021.

7. Sheikh MA. Childhood adversities and chronic conditions: examination of mediators, recall bias and age at diagnosis. Int J Public Health. 2018;63(2): 181-92. https://doi.org/10.1007/s00038-017-1021-2.

8. Hughes K, Bellis MA, Hardcastle KA, Sethi D, Butchart A, Mikton C, Jones L, Dunne MP. The effect of multiple adverse childhood experiences on health: a systematic review and meta-analysis. Lancet Public Health. 2017;2(8):e35666. https://doi.org/10.1016/S2468-2667(17)30118-4.

9. Bright MA, Knapp C, Hinojosa MS, Alford S, Bonner B. The comorbidity of physical, mental, and developmental conditions associated with childhood adversity: a population based study. Matern Child Health J. 2016;20(4):84353. https://doi.org/10.1007/s10995-015-1915-7.

10. Campbell JA, Walker RJ, Egede LE. Associations between adverse childhood experiences, high-risk behaviors, and morbidity in adulthood. Am J Prevent Med. 2016;50(3):344-52. https://doi.org/10.1016/j.amepre.2015.07.022.

11. Atkinson L, Beitchman J, Gonzalez A, Young A, Wilson B, Escobar M Chisholm V, Brownlie E, Khoury JE, Ludmer J, Villani V. Cumulative risk, cumulative outcome: a 20-year longitudinal study. PloS One. 2015;10(6): e0127650. https://doi.org/10.1371/journal.pone.0127650.

12. Gilbert LK, Breiding MJ, Merrick MT, Thompson WW, Ford DC, Dhingra SS, Parks SE. Childhood adversity and adult chronic disease: an update from ten states and the District of Columbia, 2010. Am J Prevent Med. 2015;48(3): 345-9. https://doi.org/10.1016/j.amepre.2014.09.006.

13. Kerker BD, Zhang J, Nadeem E, Stein RE, Hurlburt MS, Heneghan A, Landsverk J, Horwitz SM. Adverse childhood experiences and mental health, chronic medical conditions, and development in young children. Acad Pediatr. 2015;15(5):510-7. https://doi.org/10.1016/j.acap.2015.05.005.

14. Mitchell KJ, Tynes B, Umaña-Taylor AJ, Williams D. Cumulative experiences with life adversity: identifying critical levels for targeting prevention efforts. J Adolesc. 2015;43:63-71. https://doi.org/10.1016/j.adolescence.2015.05.008.

15. Campbell JA, Mendez CE, Garacci E, Walker RJ, Wagner N, Egede LE. The differential impact of adverse childhood experiences in the development of pre-diabetes in a longitudinal cohort of US adults. J Diab Compl. 2018; 32(11):1018-24. https://doi.org/10.1016/j.jdiacomp.2018.09.006. 
16. Kalmakis KA, Chandler GE. Adverse childhood experiences: towards a clear conceptual meaning. J Adv Nurs. 2014;70(7):1489-501. DOI: https://doi.org/ 10.1111/jan.12329.

17. Pechtel P, Pizzagalli DA. Effects of early life stress on cognitive and affective function: an integrated review of human literature. Psychopharmacology. 2011;214(1):55-70. https://doi.org/10.1007/s00213-010-2009-2.

18. Burrus B, Leeks KD, Sipe TA, Dolina S, Soler R, Elder R, Barrios L, Greenspan A, Fishbein D, Lindegren ML, Achrekar A. Person-to-person interventions targeted to parents and other caregivers to improve adolescent health: a community guide systematic review. Am J Prevent Med. 2012;42(3):316-26. https://doi.org/10.1016/j.amepre.2011.12.001.

19. DeVore ER, Ginsburg KR. The protective effects of good parenting on adolescents. Curr Opin Pediatr. 2005;17(4):460-5. https://doi.org/10.1097/01. mop.0000170514.27649.c9.

20. Klemera E, Brooks FM, Chester KL, Magnusson J, Spencer N. Self-harm in adolescence: protective health assets in the family, school and community. Int J Public Health. 2017;62(6):631-8. https://doi.org/10.1007/s00038-0160900-2.

21. Tabak I, Mazur J. Social support and family communication as factors protecting adolescents against multiple recurrent health complaints related to school stress. Dev Period Med. 2016;20(1):27-39. 27416623.

22. Elgar FJ, Craig W, Trites SJ. Family dinners, communication, and mental health in Canadian adolescents. J Adolesc Health. 2013;52(4):433-8. https:// doi.org/10.1016/j.jadohealth.2012.07.012.

23. Berryhill MB, Harless C, Kean P. College student cohesive-flexible family functioning and mental health: examining gender differences and the mediation effects of positive family communication and self-compassion. Fam J. 2018;26(4):422-32. https://doi.org/10.1177\%2F1066480718807411.

24. Beiter R, Nash R, McCrady M, Rhoades D, Linscomb M, Clarahan M, Sammut $\mathrm{S}$. The prevalence and correlates of depression, anxiety, and stress in a sample of college students. J Affect Disord. 2015;173:90-6. https://doi.org/ 10.1016/j.jad.2014.10.054

25. Moore GF, Cox R, Evans RE, Hallingberg B, Hawkins J, Littlecott HJ, Long SJ Murphy S. School, peer and family relationships and adolescent substance use, subjective wellbeing and mental health symptoms in wales: a cross sectional study. Child Indicators Res. 2018;11(6):1951-65. https://doi.org/10. 1007/s12187-017-9524-1.

26. Barrett PM, Duffy AL, Dadds MR, Rapee RM. Cognitive-behavioral treatment of anxiety disorders in children: Long-term (6-year) follow-up. J Consult Clin Psychol. 2001;69(1):135. https://psycnet.apa.org/doi/10.1037/0022-006X.6 9.1 .135$.

27. Su S, Wang X, Pollock JS, Treiber FA, Xu X, Snieder H, McCall WV, Stefanek M, Harshfield GA. Adverse childhood experiences and blood pressure trajectories from childhood to young adulthood: the Georgia stress and heart study. Circulation. 2015;CIRCULATIONAHA-114. (https://doi.org/10. 1161/CIRCULATIONAHA.114.013104).

28. Danese A, Moffitt TE, Harrington H, Milne BJ, Polanczyk G, Pariante CM, Poulton R, Caspi A. Adverse childhood experiences and adult risk factors for age-related disease: depression, inflammation, and clustering of metabolic risk markers. Arch Pediatr Adolesc Med. 2009;163(12):1135-43. https://doi. org/10.1001/archpediatrics.2009.214

29. Noble KG, Houston SM, Kan E, Sowell ER. Neural correlates of socioeconomic status in the developing human brain. Dev Sci. 2012;15(4): 516-27. https://doi.org/10.1111/j.1467-7687.2012.01147.x.

30. Hanson JL, Nacewicz BM, Sutterer MJ, Cayo AA, Schaefer SM, Rudolph KD, Shirtcliff EA, Pollak SD, Davidson RJ. Behavioral problems after early life stress: contributions of the hippocampus and amygdala. Biol Psychiatr. 2015; 77(4):314-23. https://doi.org/10.1016/j.biopsych.2014.04.020.

31. Holubcikova J, Kolarcik P, Geckova AM, Reijneveld SA, van Dijk JP. Regular energy drink consumption is associated with the risk of health and behavioural problems in adolescents. Eur J Pediatr. 2017;176(5):599-605. https://doi.org/10.1007/s00431-017-2881-4

32. Goodman R, Meltzer H, Bailey $V$. The strengths and difficulties questionnaire: a pilot study on the validity of the self-report version. Eur Child Adolesc Psychiatr. 1998;7(3):125-30. https://doi.org/10.1007/s007870050057.

33. Goodman A, Lamping DL, Ploubidis GB. When to use broader internalising and externalising subscales instead of the hypothesised five subscales on the strengths and difficulties questionnaire (SDQ): data from British parents, teachers and children. J Abnorm Child Psychol. 2010;38(8):1179-91. https:// doi.org/10.1007/s10802-010-9434-x.
34. Baglivio MT, Wolff KT, Piquero AR, Epps N. The relationship between adverse childhood experiences (ACE) and juvenile offending trajectories in a juvenile offender sample. J Criminal Justice. 2015;43(3):229-41. https://doi.org/10. 1016/j.jcrimjus.2015.04.012.

35. Kelly-Irving M, Lepage B, Dedieu D, Bartley M, Blane D, Grosclaude P, et al. Adverse childhood experiences and premature all-cause mortality. Eur J Epidemiol. 2013;28(9):721-34. https://doi.org/10.1007/s10654-013-9832-9.

36. Ramiro LS, Madrid BJ, Brown DW. Adverse childhood experiences (ACE) and health-risk behaviors among adults in a developing country setting. Child Abuse Neglect. 2010;34(11):842-55. https://doi.org/10.1016/j.chiabu. 2010.02.012.

37. Elgar FJ, Pförtner TK, Moor I, De Clercq B, Stevens GW, Currie C. Socioeconomic inequalities in adolescent health 2002-2010: a time-series analysis of 34 countries participating in the health behaviour in school-aged children study. Lancet. 2015;385(9982):2088-2095. DOl: https://doi.org/10. 1016/S0140-6736(14)61460-4.

38. Ohannessian CM, De Los Reyes A. Discrepancies in adolescents' and their mothers' perceptions of the family and adolescent anxiety symptomatology. Parenting. 2014;14(1):1-8. https://doi.org/10.1080/15295192.2014.870009.

39. O'Shea G, Spence SH, Donovan CL. Interpersonal factors associated with depression in adolescents: are these consistent with theories underpinning interpersonal psychotherapy? Clin Psychol Psychother. 2014;21(6):548-58. https://doi.org/10.1002/cpp.1849.

40. Lamis DA, Jahn DR. Parent-child conflict and suicide rumination in college students: the mediating roles of depressive symptoms and anxiety sensitivity. J Am Coll Health. 2013;61(2):106-13. https://doi.org/10.1080/ 07448481.2012 .754758

41. Paclikova K, Veselska ZD, Bobakova DF, Palfiova M, Geckova AM. What role do family composition and functioning play in emotional and behavioural problems among adolescent boys and girls? Int J Public Health, DOI. 2019; 64(2):209-17 https://doi.org/10.1007/s00038-018-1171-x.

42. Bellon-Champel L, Varscon I. Family and substances use in adolescence: vulnerability and adaptation factors. Ann Méd Psychol. 2017;175:313-9. https://doi.org/10.1016/j.amp.2015.06.005.

43. Parent-Boursier C, Hébert M. Security in father-child relationship and behavior problems in sexually abused children. J Fam Violence. 2015;30(1): 113-22. https://doi.org/10.1007/s10896-014-9653-y.

44. Paquette $D$. Theorizing the father-child relationship: mechanisms and developmental outcomes. Hum Dev. 2004;47(4):193-219. https://doi.org/10. $1159 / 000078723$.

45. Paquette D. Dichotomizing paternal and maternal functions as a means to better understand their primary contributions. Hum Dev. 2004;47(4):237. https://doi.org/10.1159/000078726.

46. Paquette D, Bolté C, Turcotte G, Dubeau D, Bouchard C. A new typology of fathering: defining and associated variables. Infant Child Dev, DOl. 2000;9(4): 213-30 https://doi.org/10.1002/1522-7219(200012)9:4\%3C213::AID-ICD233\% 3E3.0.CO;2-0.

47. Parent-Boursier C, Hébert M. La perception de la relation père-enfant et l'adaptation des enfants suite au dévoilement d'une agression sexuelle. Can J Behav Sci. 2010;42(3):168. https://psycnet.apa.org/doi/10.1037/a0017691.

48. Goodman ES, Ford CA, Friedrich EA, Ginsburg KR, Miller VA, Mirman JH. Frequency of communication about adolescents' strengths and weaknesses and the parent-adolescent relationship. Appl Dev Sci. 2019;13:1-2. https:// doi.org/10.1080/10888691.2019.1594813.

49. Riesch SK, Anderson LS, Krueger HA. Parent-child communication processes: preventing children's health-risk behavior. J Special Pediatr Nurs. 2006;11(1):41-56. https://doi.org/10.1111/j.1744-6155.2006.00042.x.

50. Aunola K, Nurmi JE. The role of parenting styles in children's problem behavior. Child Dev. 2005;76(6):1144-59. https://doi.org/10.1111/j.1467-8624. 2005.00840.x-i1.

51. Muris P, Meesters $C$, van den Berg F. The strengths and difficulties questionnaire (SDQ). Eur Child Adolesc Psychiatr. 2003;12(1):1-8. https://doi. org/10.1007/s00787-003-0298-2.

52. Meinck F, Cosma AP, Mikton C, Baban A. Psychometric properties of the adverse childhood experiences abuse short form (ACE-ASF) among Romanian high school students. Child Abuse Neglect. 2017;72:326-37. https://doi.org/10.1016/j.chiabu.2017.08.016.

\section{Publisher's Note}

Springer Nature remains neutral with regard to jurisdictional claims in published maps and institutional affiliations. 